\title{
Translation of Negative Politeness Strategies from English into Persian: The Case of Novel Translation
}

\author{
Negar Moradi \\ E-mail: negar247@yahoo.com \\ Mohammad Jafar Jabbari (Corresponding Author) \\ Yasouj University, Iran \\ E-mail: mjjabbari@yu.ac.ir
}

English Department, School of Foreign Languages, Fars Science and Research Branch, Islamic Azad University, Marvdasht, Iran

Received: 17-08-2014

doi:10.7575/aiac.ijalel.v.4n.2p.143
Accepted: 23-10-2014

Published: 01-03-2015

\begin{abstract}
Since the 1970s the phenomenon of politeness theory has come to the fore as one of the areas of applied linguistics. This notion has recently played a pivotal role in the realm of translation studies as well. However, the number of research projects in this area of translation studies, especially in English and Persian, is very small. This scantiness was among the rationales behind conducting the present study. This study aimed at investigating the translation strategies used by Persian translators in translating negative politeness strategies as well as translation quality assessment (TQA) of these pragmatic structures. To this end, two research questions regarding the translation strategies as well as TQA were defined, and the novel 'Grapes of Wrath' was selected as the material of the study. Using Brown \& Levinson's (1987) politeness theory, the novel was analyzed and a bulk of 100 utterances encompassing negative politeness strategies was randomly selected and juxtaposed with their Persian translations. Then, they were analyzed based on Newmark's (1988) translation strategy as well as Rahimi's (2004) translation theory and Zamani's (2013) TQA framework. The results of the data analysis indicated that from among Newmark's 16 translation strategies, 6 strategies proved to be more beneficial to translate negative politeness strategies. Moreover, the findings of the study proved that the level of Persian translation quality was at an average level, implying the fact that even professional translators require a higher mastery of pragmatic aspects of language- politeness theory in this respect.
\end{abstract}

Keywords: Translation, negative politeness sub-strategies, translation strategies, translation quality assessment (TQA), face-threatening acts (FTAs)

\section{Introduction}

From among different versions of politeness theory, Brown and Levinson's (1978) proposed model has been the most comprehensive one (Yaqubi \& Afghari, 2011). Even though Brown \& Levinson (1987) claimed that their model is a universal one, different research projects (such as Akbari, 2002; Yaqubi\&Afghari, 2011) have questioned this claim due to the fact that the politeness phenomenon is a culture-dependent pragmatic aspect of language. This culture specificity makes the task of translation of these pragmatic structures more problematic and complex. The more complex a structure, the more translation strategies would be required during the process of translation (Zamani, 2013). Furthermore, in order to for a translator to accurately render a pragmatic phenomenon from the source language (SL) into the target language (TL), a mastery of different areas of pragmatics is required on the part of the translator (Zamani, 2013).

\section{Background}

To date, a large number of research projects have been conducted in the realm of politeness theory. Most of these studies, however, have mainly focused on cross-linguistic or cross-cultural analysis of the politeness strategies in different languages. Nonetheless, there are a scant number of studies regarding the translation of politeness strategies, especially in English and Persian. To the best of the researchers' knowledge, Yaqubi \& Afghari's (2011) research project has been the only study done on the translation of politeness strategies from English into Persian.

In their study, Yaqubi \&Afghari (2011) investigated the translation of negative and off-record politeness strategies from English into Persian in the context of American movies. They limited their scope of the study to the speech act of request. Their study aimed at: a) determining the types of politeness strategies used in English and Persian, b) investigating both Persian and English with respect to the usage of the politeness strategies, and c) exploring the types of translation strategies utilized in the Persian translations of English requests. Selecting 30 requestive utterances, Yaqubi \&Afghari asked $30 \mathrm{MA}$ and $\mathrm{PhD}$ students of translation studies to translate them. The results of their 
investigation proved fourteen negative and off-record politeness sub-strategies (used in English and Persian) more common than the others. On the other hand, the findings of their study indicated that the sub-strategy of being pessimistic was the only point of differentiation between English and Persian. Their study further showed that from among Newmark's (1988) translation strategies seven strategies were used in Persian translations of English requests.

In another study, Akbari (2002) investigated the patterns of realization of different politeness strategies in English and Persian. Observing differences and similarities between English and Persian with respect to the patterns of manifestation of politeness strategies, Akbari came to this point that there are some areas of divergence from Brown \& Levinson's (1987) politeness model. To mention a few, regarding the negative politeness strategies, the areas of 'nominalizing' and 'giving deference' were more culture specific than the others. Coming to this conclusion, Akbari questioned the universality of Brown \& Levinson's politeness model.

Other empirical studies done in the realm of politeness theory have focused on the patterns of politeness realizations in Persian culture (Beeman, 1976; Assadi, 1980; Beeman 1986). On the other hand, there are a good number of studies conducted on politeness realization patterns in different languages worldwide. A few of these cross-cultural and crosslinguistic studies are including: Australian English, Canadian French, German, Hebrew, and Argentine Spanish (BlumKulka, House, \& Kasper 1989); Greek and British English (Sifianou 1992); Hebrew and American English (BlumKulka 1987); Peninsular Spanish (LePair 1996); Uruguayan Spanish and British English (Marquez-Reiter 2000); Polish (Wierbzicka 2003); and Peninsular and Colombian Spanish (Delgado 1994).This scarcity of empirical research in this area of translation studies has been one of the rationales behind conducting the present study.

The present study aimed at providing translators with some translation strategies beneficial for translating negative politeness strategies, illuminating the similarities and differences between English and Persian with respect to the type of negative politeness strategies used, and assessing the translation quality of these pragmatic structures. To this end, the following research questions were raised:

1. What translation strategies have been employed by the Persian translator of the selected English novel in rendering negative politeness strategies?

2. To what extent have the Persian translations of English negative politeness strategies rendered the exact degree of politeness aspect?

\section{Data and Method of the Study}

The present study utilized four different theories as its frameworks. With respect to the analysis of the source text and the target text utterances in terms of the negative politeness strategies, Brown and Levinson's (1987) politeness theory was employed as the 'pragmatic framework' of the study. Newmark's (1988) translation strategies, on the other hand, were used as the 'translation framework' for determining the types of translation strategies utilized by the Persian translators in rendering negative politeness strategies. As for the translation quality assessment of the negative politeness strategies, a combination of Zamani's (2013) TQA framework and Rahimi's (2004) translation theory was employed in the study as the 'TQA framework.'

To conduct this study, John Steinbeck's (1939) The Grapes of Wrath, translated by Sharifian (2008) and Maskoob \& Ahmadi (1964) into Persian as "Khoshe-ha-ye Khashm" was selected as the material of the study. In order to quantify the qualitative data gathered, and to present them in a more meaningful way, a set of descriptive statistics including, frequency, percentage, mean score, total score, and mode was used.

Using Brown \& Levinson's (1987) politeness theory, the utterances of the novel were analyzed and the types of politeness strategies were determined. Delineating the utterances encompassing the negative politeness strategies, 100 utterances were randomly selected and juxtaposed with their Persian translations. Then, they were analyzed based on Newmark's (1988) translation strategy as well as Rahimi's (2004) translation theory and Zamani's (2013) TQA framework. With respect to the first research question, after determining the frequencies and percentages of the occurrence of translation strategies, a conclusion was made and some useful translation strategies were proposed. With respect to the second question of the research, the definitions of the triangle of TQA (that is, accuracy, clarity, and naturalness) were adopted from Rahimi (2004) and the method of scoring the translations was taken from Zamani's (2013) TQA framework in which the scores of 1,2, 3, and 4 are assigned to the unsuccessful, relatively successful, successful, and completely successful translations, respectively (see Zamani, 2013 for a detailed discussion).

\section{Data Analysis and Results}

With respect to the first question of the study, the results of the data analysis proved that different translation strategies were simultaneously involved in translation of negative politeness strategies. Furthermore, the findings of the study indicated that from among Newmark's (1988) 16 translation strategies, 6 strategies were more beneficial for translating negative politeness strategies. Table 1. shows the frequencies and percentages of the translation strategies involved in the translation of negative politeness strategies. 
Table 1.Frequency and percentage of each translation strategy

\begin{tabular}{lll}
\hline Newmark's strategies & Frequency & Percentage \\
\hline Literal translation & 118 & $20.6 \%$ \\
Transference & 8 & $1.3 \%$ \\
Naturalization & 0 & 0 \\
Through-translation & 17 & $2.9 \%$ \\
Cultural equivalent & 36 & $6.3 \%$ \\
Functional equivalent & 84 & $14.7 \%$ \\
Descriptive equivalent & 27 & $4.7 \%$ \\
Compensation & 4 & $0.6 \%$ \\
Expansion & 168 & $29.1 \%$ \\
Reduction & 52 & $8.9 \%$ \\
Synonymy & 23 & $3.3 \%$ \\
Paraphrase & 0 & 0 \\
Transposition & 18 & $3 \%$ \\
Modulation & 21 & $3.8 \%$ \\
Componential analysis & 5 & $0.8 \%$ \\
Recognized translation & 0 & 0 \\
Translation label & 0 & 0 \\
Total & 581 & $100 \%$ \\
\hline
\end{tabular}

As Table 1.shows, expansion, literal translation, and functional equivalents are among the very highly frequent translation strategies. On the other hand, reduction, cultural equivalent, and descriptive equivalent are located in the high frequency position of the continuum. Furthermore, modulation, synonymy, transposition, and through translation are among the translation strategies of low frequency. Finally, the translation strategies of transference, componential analysis, and compensation are located at the last position of frequency, that is, very low. With reference to these results, the 6 translation strategies of high and very high frequency are regarded as the most useful strategies in translating negative politeness strategies. In what follows, a few examples will be illustrated and discussed in detail in order to investigate how these strategies have been employed in the translation of negative politeness strategies. It is noteworthy that, in the following examples, the abbreviations TT1 and TT2 are used to stand for translations of Sharifian(2008) and Maskoob \& Ahmadi (1964), respectively, in order to prevent repetition and save space .

(1)

SL: Like me to he'p you get them valves set an' the head on? (Questioning/Hedging \& Giving Deference)

\section{TL1: /?ejaze midin komæketun konæm supap-ha ro sævar konim væreglazefun konæm/}

Politeness sub-strategies in TL1:

- Questioning/Hedging: /?ejaze midin/

- Giving Deference: Using third person plural suffix /midin komæketun/

Translation strategies:

- Expansion: /?ejazemidin / / reglaze Jun konæm/

- Literal translation: /komæketun konæm supap-ha ro sævar konim/

TL2: /mixaj bæraj-e kargoza ftæn-e supapa væ dære behet komæk konæm/

Politeness sub-strategies in TL2:

- Questioning: Using question as an offer

Translation strategies:

- Literal translation: /mixaj//supapa væ dære / /behet komæk konæm/

- Transposition: /kar gozaftæn-e/

In example 1, the context of situation as well as the level of power, intimacy, and rank of imposition between the speaker of the utterance and the addressee shows a kind of formality that requires a little politeness even at the time of offering. In this regard, a person who has not read this novel cannot recognize this situation. In TL1, the translator has delicately applied two negative politeness strategies, namely, questioning/hedging and giving deference, by using expansion and literal translation as two translation strategies, leading to rendering the same negative politeness strategies of the SL in the TL1. In other words, while in TL2, the translator has maintained the linguistic form of the SL utterance in TL2, leading to a relatively literal translation whose level of negative politeness is different from that of the SL utterance. It is crystal clear that TL2 lacks the negative politeness strategy of giving deference. However, the implicit negative strategy of giving deference in SL has been explicitly rendered in TL1. 
(2)

SL: Could ya come down from your thinkin' an' listen a minute? (Questioning/Hedging, Giving Deference, Being Pessimistic)

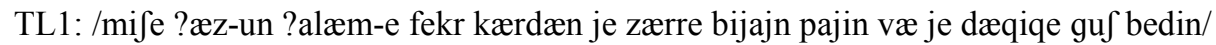

Politeness sub -strategies in TL1:

- Questioning/Hedging: /mife/

- Giving Deference: Using third person plural suffix / bijajn//bedin/

- Being pessimistic: /mife ?æz-un ?alæm-e fekr kærdæn bijajn pajin væ guf bedin/

Translation strategies:

- Expansion: /?alæme//?un//je zærre/

- Literal translation: /mi e ?æz-un fekr kærdæn je zærre bijajn pajin væ je dæqiqe gu $\int$ bedin/

- Functional equivalent: /mife/

TL2: /mitunin ?æ zfekr kærdæn birun bijajn væ ye dæqiqe be mæn guf bedin/

Politeness sub-strategies in TL2:

- Questioning/Hedging: /mitunin/

- Giving Deference: Using third person plural suffix /mitunin//bijajn//bedin/

- Being pessimistic: /mitunin ?æz fekr kærdæn birun bijajn væ ye dæqiqe be-mæn guf bedin/

Translation strategies:

- Literal translation: /mitunin/ /?æz fekr kærdæn/ / væ ye dæqiqe guf bedin/

- Functional equivalent: /?æz fekr kærdæn birun bijajn/

- Expansion: /be mæn/

In example 2, both translations have rendered the three negative politeness strategies into the TL. To be more concise, in both TL1 and TL2, the word / $\mathrm{mi} \mathrm{e}$ / and /mitunin/ have simultaneously conveyed the negative politeness strategies of Hedging and Being Pessimistic. On the other hand, the third person plural suffixes have been utilized to render the strategy of Giving Deference. However, in terms of usage, the word /mife/ is better than /mitunin/ in such a situation. Moreover, in TL1, the literal translation of [come down from your thinkin'] as /?æz un fekr kærdæn je zærre bijajn pajin/ sounds unnatural in the TL. This unnaturalness has been eliminated by using a functional equivalent in TL2. Consequently, with respect to the accuracy and clarity of translation, both TL1 and TL2 are successful while there are some drawbacks in terms of naturalness.

(3)

SL: Owners don't want us to pick up nobody. So we got to set here an' just skin her along. (Stating the FTA as a General Rule)

TL1: /sahebaj-e kamijuna ?edzaze nemidæn ma mosafer sævar konim. ma hæm dige natfarim tæk-o tænha be finim væ ranændegi konim./

Politeness sub -strategies in TL1:

- $\quad$ Stating the FTA as a general rule: The whole utterance

Translation strategies:

- Modulation: /?edzaze nemidæn/

- Expansion: / kamijuna/ / mosafer/ / dige/ /tæk-o tænha/

- Functional equivalent: /?edzaze nemidæn/ /tæk-o tænha befinim væ ranændegi konim/

TL2: /?ærbab-ha nemizaræn mosafer begirim. Bajæd tæk-o-tænha poft-e rol gæz kærd./

Politeness sub-strategies in TL2:

- $\quad$ Stating the FTA as a general rule: The whole utterance

Translation strategies:

- Functional equivalent: /?ærbab-ha nemizaræn mosafer//poft-e rol gæzkærd/

- Expansion: / mosafer//tæk-o-tænha/

- Modulation: /nemizaræn/ 
In example 3, both TL1 and TL2 have accurately rendered the negative translation strategy of Stating the FTA as a General Rule through utilizing the aforementioned translation strategies. It should be mentioned that albeit both TL1 and TL2 are successful in terms of accuracy and clarity, TL1 is more acceptable with respect to the factor of naturalness.

(4)

SL: If it hits you wrong, don't take no offence at it, will you? (Hedging \& Minimizing the Imposition)

TL1: /?æge ?æz ?una xofet næjumæd, delxor næfi-ja, bafe/

Politeness sub -strategies in TL1:

- Hedging: /?æge/

- Minimizing the Imposition: /delxor næeji-ja/ /baee/

Translation strategies:

- Expansion: /?æz/

- Reduction: [at it]

- Functional equivalent: /?æge ?æz ?una xofet næjumæd//delxor næfi-ja//bafe/

TL2: /?æge ?æz ?in hærfa xofet nemijad, æqællæn behet bær-nemixore ke/

Politeness sub-strategies in TL2:

- Hedging: /?æge/

- Being Pessimistic: / æqællæn behet bær-nemixore ke /

\section{Translation strategies:}

- Functional equivalent: /?æge ?æz ?in hærfa xofet nemijad/

- Expansion: /?æz/ /hærfa//æqællæn//ke/

- Literal translation:/behet bær-nemixore/

In example 4, TL1 has accurately and naturally rendered the negative politeness strategies (that is, Hedging \& Minimizing the Imposition) of the SL utterance into the TL, employing appropriate translation strategies. However, in terms of clarity, the first part of the utterance is a little bit problematic since the reference of the pronoun /?una/ in TL1 is not clear enough to comprehend. To clarify, it would be better to make the implicit part of this pronoun explicit, as what the second translator has done through employing expansion strategy (that is, /?inharfa/). On the other hand, in TL2, in spite of rendering the negative politeness strategy of Hedging, it has wrongly conveyed the strategy of Being Pessimistic instead of Minimizing the Imposition. This has been due to using wrong translation strategies of Literal translation (/behet bær-nemixore/) and Expansion (/æqællæn//ke/). Consequently, TL2 lacks accuracy and clarity, leading to an unacceptable translation.

In order to illustrate the results of the second question of the study regarding the assessment of translation quality of the negative politeness strategies, a few examples will be presented and discussed below.

(5)

SL: Whyn't you lay a minute till it warms? (Conventionally Indirect, Minimizing the Imposition)

TL1: /tferanemixabi ta hæva je kæmgærmfe/

Politeness sub -strategies in TL1:

- Conventionally Indirect: Using interrogative form to convey speech act of offer.

- Minimizing the Imposition: Indirectly imposing the FTA, and offering instead of commanding.

Translation strategies:

- Expansion: /je kæm//hæva/

- Reduction: [a minute]

- Compensation: /je kæm/

- Literal translation: /fyera nemixabi ta//gærm Je/

TL2: /tera sæbrnemikoni hæva gærmtær befe/

Politeness sub-strategies in TL2:

- Conventionally Indirect: Using interrogative form to convey speech act of offer.

- Minimizing the Imposition: Indirectly imposing the FTA, and offering instead of commanding. 
Translation strategies:

- Reduction: [a minute]

- Expansion: /hæva/

- Modulation: /tera sæbr nemikoni/

- Transposition: /gærmtær/

In example 5, both TL1 and TL2 have rendered the abovementioned negative politeness strategies. In TL1, the translator has creatively translated the respective negative politeness strategies by using appropriate translation strategies. Technically speaking, in TL1, even though the translator has omitted the noun phrase [a minute], this phrase has been made up through the translation strategy of compensation by using the adverbial phrase /je kæm/. This translation covers the triad of accuracy, clarity, and naturalness and thus stands in the fourth position of translation quality cline, i.e., completely successful translation whose score is 4.

On the other hand, TL2 is acceptable; however, it has employed the translation strategy of modulation which is unnecessary and unjustifiable. Hence, it would be better to use the literal translation of the word [lay] instead of /sæbrkærdæn/, even though it has nothing to do with rendering the exact negative politeness strategy. This translation is also regarded as a completely successful one with the score 4.

(6)

SL: Could ya come down from your thinkin' an' listen a minute? (Questioning/Hedging, Giving Deference, Being Pessimistic)

TL1: /mife ?æz-un ?alæm-e fekr kærdæn je zærre bijajn pajinv æ je dæqiqe gu $\int$ bedin/

Politeness sub -strategies in TL1:

- Questioning/Hedging: /mife/

- Giving Deference: Using third person plural suffix / bijajn//bedin/

- Being pessimistic: /mife ?æz-un ?alæme fekr kærdæn bijajn pajin væ guf bedin/

Translation strategies:

- Expansion: /?alæme/ /?un/ /je zærre/

- Literal translation: /mi e ?æz un fekr kærdæn je zærre bijajn pajinvæ je dæqiqe guf bedin/

- Functional equivalent: /mife/

TL2: /mitunin ?æz fekr kærdæn birun bijajnvæ ye dæqiqe be mæn gu $\int$ bedin/

Politeness sub-strategies in TL2:

- Questioning/Hedging:/mitunin/

- Giving Deference: Using third person plural suffix /mitunin//bijajn//bedin/

- Being pessimistic: /mitunin ?æz fekr kærdæn birun bijajn væ ye dæqiqe be mæn gu $\int$ bedin/

Translation strategies:

- Literal translation: /mitunin/ /?æz fekr kærdæn/ / væ ye dæqiqe guf bedin/

- Functional equivalent: /?æz fekr kærdæn birun bijajn/

- Expansion: /be mæn/

In example 6, both TL1 and TL2 have rendered the three negative politeness strategies. In the two translations, the word /mife/ and /mitunin/ have simultaneously conveyed the negative politeness strategies of Hedging and Being Pessimistic. On the other hand, the third person plural suffixes have been utilized to render the strategy of Giving Deference. However, in terms of usage, the word /mife/ is better than /mitunin/ among Persian speakers in such a situation. Moreover, in TL1, the literal translation of [come down from your thinkin'] by /?æz un fekrkærdæn je zærrebijajnpajin/ sounds unnatural. This unnaturalness has been eliminated by using a functional equivalent in TL2. Consequently, with respect to the accuracy and clarity of translation, both translations are acceptable while there are some drawbacks in terms of naturalness. In Zamani's (2013) framework, such a translation stands in the third position of the cline, i.e., successful translation (whose score is 3 ).

The following table presents the descriptive statistics for each Persian translation with respect to their quality.

Table 2. Descriptive statistics with respect to the translation quality of TT1 and TT2

\begin{tabular}{lllll}
\hline Translators & Mean of scores & Total score & Mode & Number of items \\
\hline Sharifian & 3.1 & 312 & 3 & 100 \\
Maskoob \& Ahmadi & 2.3 & 231 & 2 & 100 \\
\hline
\end{tabular}


As Table 2.shows, With reference to the aggregated results, the mean scores and the mode of Sharifian's (2008) (TT1) translation are 3.1 and 3, respectively. These results demonstrate the fact that Sharifian's translation of negative politeness strategies stands at the third level of translation quality, i.e., successful translation. On the other hand, the gained results show that the mean scores and the mode of Maskoob\&Ahmadi's (1964) (TT2) translation are 2.3 and 2, respectively. This reveals the fact that Maskoob \& Ahmadi's translations are placed at the second point of the translation quality continuum, namely, relatively successful translation.

\section{Discussion}

As to the frequency of translation strategies, the results of the present study are to some extent in the same line with those of Yaqubi\&Afghari (2011). In terms of the highly frequent translation strategies, the results of the present study are the same as those of Yaqubi \& Afghari. That is to say, three translation strategies of expansion, literal translation, and functional equivalent have been reported to be amongst the very high frequent translation strategies both in their study and in the present study. This shows the fact that the aforementioned translation strategies, as stated by Yaqubi \& Afghari (2011), are amongst the most useful translation strategies that can facilitate the process of translation of politeness strategies (negative politeness strategies, in this case). However, with respect to the highly frequent strategies the results of the present study are not the same as those of Yaqubi and Afghari (2011).

\section{Applications}

The findings of this study can be applied in different areas of language. These findings provide translators with some insights regarding interpretation, understanding and translating politeness strategies in daily oral or written communication. Moreover, they can be of interest to different scholars in such areas as translation, linguistics, sociolinguistics and pragmatics. In addition, the findings of the translation quality assessment part of the study are useful in the realm of Translation Quality assessment.

Accordingly, the findings of the present study can help translators improve their level of pragmatic competency, at the minimum, in the area of politeness, which can result in improving the quality of translation. Furthermore, the outcomes of the present study can help ESL/EFL teachers to expose their students to some reliable sources of pragmatic information as to their mother tongue and the second/foreign language to be learned.

\section{Conclusions}

With respect to the first question of the study, the results indicated that from among the 16 translation strategies proposed by Newmark (1988), 6 strategies were more frequent than the others. Besides, according to the observations of the study, these 6 strategies proved to be the most beneficial and influential strategies in translating negative politeness strategies of the selected novel. These 6 strategies were: (a) expansion, (b) literal translation, (c) functional equivalents, (d) reduction, (e) cultural equivalent, and (f) descriptive equivalent. The rest of Newmark's (1988) strategies, however, proved not to be much important in translating negative politeness strategies. Furthermore, the study showed that there were a large number of translation strategies involved in the translation of each utterance of negative politeness strategy, indicating that the translation of these pragmatic structures is problematic and needs competency of pragmatic issues, on the part of the translator, to overcome the challenges.

Regarding the second question of the study, translation quality assessment indicated that Sharifian's(2008) translation of negative politeness strategies stands at the third level of translation quality, i.e., successful translation, while Maskoob \& Ahmadi's(1964) translation is located at the second point of the translation quality continuum, namely, relatively successful translation, illustrating that Sharifian's translation is one level above the Maskoob \& Ahmadi's. As the results demonstrate, none of these two translations stands at the fourth level of translation quality, i.e., completely successful translation. This proves the fact that even professional translators need the achievments of translation studies such as those of the present study in order to improve their quality of translation. Consequently, a competent translator must have mastery of pragmatic issues of the languages involved in the process of translation as well as linguistic issues.

\section{References}

Akbari, Z. (2002). The realization of politeness principles in Persian. Karen Linguistics Issues. Retrieved October 12 , 2013, fromhttp://www.telus.net/linguisticsissues/

Assadi, R. (1980). Deference: Persian style. Anthropological Linguistic, 22 (5), 221-224.

Beeman, W. (1976).Status, style and strategy in Iranian interaction. Anthropological Linguistic, 14 (6), 305-322.

Beeman, W. (1986).Language, status, and power in Iran. Bloomington: Indiana University press.

Blum-Kulka, Sh. (1987). Indirectness and politeness in requests: Same or different? Journal of Pragmatics, 11 (7), 131146.

Blum-Kulka, Sh., House, J., \& Kasper, G. (1989).Cross-cultural pragmatics: Requests and apologies. Norwood: Ablex Publishing.

Brown, P., \& Levinson, S. (1987). Politeness: Some universals in language usage. Cambridge: Cambridge University Press. 
Delgado, V.L. (1994). Politeness in language: Directive speech acts in U.S. English, and Colombian and Castilian Spanish (Doctoral Dissertation). State University of New York, Stony Brook, USA.

Hatim, B., \& Mason, I. (1990).Discourse and the translator. The United States of America: Longman Group UK limited.

Le Pair, R. (1996). Spanish request strategies: A cross-cultural analysis from an intercultural perspective. Language Science, 18 (6), 651-670.

Márquez-Reiter, R. (2000). Linguistic politeness in Britain and Uruguay: A contrastive study of requests and apologies. Philadelphia, PA: John Benjamins.

Newmark, P. (1988). A textbook of translation. England: Prince Hall International.

Rahimi, R. (2004). Alpha, beta and gamma features in translation: Toward the objectivity of testing translation. Translation Studies, 2 (1), 53-64.

Sifianou, M. (1992).Politeness phenomena in England and Greece: A cross-cultural perspective. Oxford, UK: Longman.

Steinbeck, J. (1939). The Grapes of Wrath [E-reader version, if applicable]. Retrieved November 15, 2012, from http:// 142.23.40.13/big/english/novels/GrapesOfWrath.

Steinbeck, J. (1964). The Grapes of Wrath. (S. Maskoob \& A. Ahmadi Trans.). Tehran: Amirkabir Publications. (original work published 1939).

Steinbeck, J. (2008). The Grapes of Wrath.(A. Sharifian Trans.). Tehran: EntesharateNegah. (original work published 1939).

Wierzbicka, A. (2003). Cross-cultural pragmatics: The semantics of human interaction (2 ${ }^{\text {nd }}$ ed.). Berlin: Mouton de Gruyter.

Yaqubi, M., \& Afghari, A. (2011). A cross-cultural study of politeness strategies applied in translations of English requests as face-threatening acts into Persian. International Journal of Education \& Social Sciences, 1 (4), 1-22.

Zamani, M. (2013).Persian translation of directive and expressive speech acts in Death of a Salesman, A Streetcar Named Desire, and Mourning Becomes Electra(Master's Thesis). Sheikhbahaee University of Isfahan, Isfahan, Iran. 